\title{
LA LÓGICA DE LO «IRRACIONAL»: GUERRA Y VIOLENCIA EN EL SALVADOR
}

Tania Ocampo Saravia

Universidad Nacional Autónoma de México taniaos@unam.mx

Recepción:

7 de julio de 2017

Aceptación:

28 de julio de 2017 


\section{RESUMEN}

El presente artículo retoma parte de una investigación de doctorado en Estudios Latinoamericanos, en la que abordo el tema de la violencia durante la guerra civil en El Salvador (1980-1992), así como sus antecedentes. En dicho trabajo intento entender cómo durante la década de los setenta se construyeron dinámicas específicas de violencia, sobre todo ejercidas desde el estado, que culminaron con el estallamiento de una guerra civil en los años ochenta. Parto de la hipótesis de que el periodo de la guerra constituyó un momento en el cual las dinámicas preexistentes de violencia se profundizaron, a partir de la construcción de otro que se debía eliminar, también conocido como "enemigo interno".

Como se verá, se trata de la exposición de conclusiones preliminares que, de ninguna manera deben interpretarse como aseveraciones definitivas; en todo caso, busco presentar los horizontes y las preguntas sobre las que he construido la que, a mi parecer, constituye el intento de ofrecer una nueva interpretación de un fenómeno tan complejo, como lo es el de la guerra en El Salvador

\section{Palabras Clave}

Violencia, Guerra, Violencia Política, Guerrilla, El Salvador.

\section{ABSTRACT}

This article takes up part of a doctoral research in Latin American Studies, in which I address the issue of violence during the civil war in El Salvador (1980-1992), as well as its background. In this work I try to understand how during the decade of the seventies specific dynamics of violence were built, especially exercised from the state, which culminated in the outbreak of a civil war in the eighties. I start from the hypothesis that the period of the war constituted a moment in which the pre-existing dynamics of violence deepened, starting from the construction of another one that had to be eliminated, also known as "internal enemy". As will be seen, it is the exposition of preliminary conclusions that, in no way, should be interpreted as definitive assertions; In any case, I seek to present the horizons and the questions on which I have built what, in my opinion, constitutes the attempt to offer a new interpretation of a phenomenon as complex as the war in El Salvador.

\section{Keywords}

Violence, War, Politic Violence, El Salvador 


\title{
LA LÓGICA DE LO «IRRACIONAL»: GUERRA Y VIOLENCIA EN EL SALVADOR
}

\author{
Tania Ocampo Saravia \\ Universidad Nacional Autónoma de México \\ taniaos@unam.mx
}

El presente artículo retoma parte de una investigación de Doctorado en Estudios Latinoamericanos, en la que abordo el tema de la violencia durante la guerra civil en El Salvador (1980-1992), así como sus antecedentes. En dicho trabajo intento entender cómo durante la década de los 70 se construyeron dinámicas específicas de violencia, sobre todo ejercidas desde el Estado, que culminaron con el estallido de una guerra civil en los años 80 . Parto de la hipótesis de que el periodo de la guerra constituyó un momento en el cual las dinámicas preexistentes de violencia se profundizaron, a partir de la construcción de otro que se debía eliminar, también conocido como «enemigo interno».

Así, en primer lugar, referiré (de manera muy breve) cómo la violencia es un continuum en la historia salvadoreña. Por otro lado, mencionaré la complejidad de los procesos de radicalización en distintos sectores de la población, que ocurrieron por la confluencia de múltiples factores como el desarrollo económico que experimentó la región; pero, sobre todo, por el trabajo que realizaron las organizaciones político militares surgidas por aquellos años, cuyo horizonte utópico era la construcción del socialismo, en los casos más radicales. Todo esto para — finalmente- esbozar que sí existe 
algo que se puede denominar «lógica de la violencia» en una guerra y que esta se puede interpretar.

Como se verá, se trata de la exposición de conclusiones preliminares que, de ninguna manera deben interpretarse como aseveraciones definitivas; en todo caso, busco presentar los horizontes y las preguntas sobre las que he construido la que, a mi parecer, constituye el intento de ofrecer una nueva interpretación de un fenómeno tan complejo, como lo es el de la guerra en El Salvador.

\section{Nuevas formas de abordar las guerras}

Durante los últimos años, se han publicado muchos libros relativos al fenómeno de la guerra. Los textos son diversos y van desde los que abordan el tema con una mirada académica, hasta los de carácter testimonial, escritos por testigos presenciales de diversas conflagraciones ocurridas en el mundo, como periodistas, o por participantes en ellas, como soldados, hombres y mujeres. Como señala Manolo Vela Castañeda, quien aborda el conflicto guatemalteco durante la segunda mitad del siglo XX:

«La historia de la humanidad también puede ser vista como la historia (o las historias) sobre la muerte de unos en manos de otros. Las diferencias en cuanto a los motivos de la matanza, el tono emocional que el empeño en asesinar implica, las víctimas, los perpetradores, los espectadores silenciosos, las creencias y la ideología, la geografia, las razones de legitimidad frente a tales hechos, los eventos y los procesos, cambian. El hecho duro sigue siendo el mismo: unos, calificados como amenaza deben morir a fin de que otros, recobren el sentido de seguridad.» ${ }^{1}$

El hecho duro parece ser el mismo y tiene que ver con las maneras en que se aniquila a quienes son definidos como «los otros»; sin embargo, como

1 Manolo E. Vela Castañeda, «Los pelotones de la muerte. La construcción de los perpetradores del genocidio guatemalteco» (México: El Colegio de México-Centro de Estudios Sociológicos, 2014), 33. 
apunta Vela Castañeda, es evidente que no todas las guerras han sido iguales y sus particularidades tienen que ver (entre otros factores) con las dinámicas sociales de quienes se involucran en una confrontación bélica, las cuales varían de acuerdo a cada cultura y a los distintos momentos de la historia.

La guerra es un asesinato en masa organizado; sin embargo, en algunos textos, esta parece un ente lejano, casi abstracto. En algunos trabajos, las muertes son solo números y lo relevante es lo que se refiere a tácticas y estrategias. No se habla de cosas que suceden también en el campo de batalla; no se problematiza respecto a lo que implica asesinar; no se toman en consideración emociones y sentimientos, como el miedo, inherentes al ser humano. No se menciona que la guerra duele, que cansa, que implica pasar hambre y frío, que produce heridas y enfermedades. No se explicita que también es reproducción de la vida cotidiana:

«La guerra es ante todo un asesinato y, además, un duro trabajo. Por último, también está la vida cotidiana: cantaban, se enamoraban [...] En el centro siempre está la insufrible idea de la muerte, nadie quiere morir.Y aún más insoportable es tener que matar, porque la mujer da la vida. La regala. La lleva dentro durante un largo tiempo, la cuida». ${ }^{2}$

En este sentido, es fundamental evidenciar que la guerra es mucho más compleja de lo que sucede en el campo de batalla; esta no ocurre solamente en la línea de fuego: «Obviamente, la guerra ‘provoca〉 violencia. Sin embargo, una considerable cantidad de violencia en las guerras civiles carece de utilidad militar convencional y no tiene lugar en el campo de batalla». ${ }^{3}$

Se trata también de lo que sucede lejos de donde ejércitos disputan la victoria. Es la vida en ciudades hostilizadas y polarizadas políticamente, los campos devastados; la guerra es la vida en los campamentos.

2 Svetlana Alexiévich, «La guerra no tiene rostro de mujer» (Barcelona: Penguin Random House, 2016), 21.

3 Stathis N. Kalyvas, «La lógica de la violencia en la guerra civil» (Madrid: Ediciones Akal, 2010), 39 . 
«La guerra infringe las prohibiciones establecidas desde hace mucho tiempo contra la violencia, la destrucción y el asesinato, infracción que suele ir acompañada del desmoronamiento de las normas sexuales, sociales y políticas, a medida que la dominación y la brutalidad del campo de batalla se trasladan a la vida personal. Las violaciones, las mutilaciones, los maltratos y los robos son la consecuencia natural de un mundo gobernado por la fuerza, en el que los seres humanos son objetos». ${ }^{4}$

Afortunadamente, las nociones de la disciplina histórica se han transformado y, al día de hoy, hay una diversidad de enfoques desde los cuales se trata de interpretar la historia de los seres humanos. La perspectiva de género es solo un ejemplo que sirve para ilustrar cómo el objeto de estudio de los hechos del pasado se ha modificado, para dar paso a otros cuestionamientos que han traído consigo otras respuestas. De ahí que los enfoques críticos del fenómeno de las guerras sean tan pertinentes como necesarios.

En este punto, vale la pena precisar que con lo mencionado no pretendo desacreditar las obras que sobre la guerra se han escrito; sin embargo, es necesario cuestionar otros aspectos del fenómeno para dar luz respecto de acontecimientos que también ocurren en las guerras, como los que se han enunciado en líneas anteriores, y que no son menos importantes que el aspecto militar, pero que no han merecido la misma atención.

\section{El estudio de la guerra de/en El Salvador}

La preocupación por abordar otras aristas de la guerra se ha replicado en El Salvador. Durante los últimos años, se ha planteado la necesidad de estudiar el conflicto armado de la década de los 80, desde puntos de vista menos militantes y más académicos. En este ánimo, en 2010 surgió la Unidad de Investigaciones sobre la Guerra Civil Salvadoreña (UIGCS), con sede en el Instituto de Estudios Históricos, Antropológicos y Arqueológicos (IE-

4 Chris, Hedges, «La Guerra es la fuerza que nos da sentido» (Madrid: Editorial Síntesis, 2002)191. 
HAA) de la Universidad de El Salvador (UES). La UIGCS está conformada por académicos y académicas de diversas disciplinas dentro de las Ciencias Sociales y las Humanidades, provenientes de distintos países; su objetivo es «incentivar y sistematizar las investigaciones que [se realizan] sobre la guerra civil salvadoreña». ${ }^{5}$

Como parte de las actividades de la UIGCS, en 2012 se llevó a cabo el Seminario Internacional «Historia, sociedad y memoria: el conflicto armado salvadoreño en el XX aniversario de los Acuerdos de Paz», cuyo objetivo principal era reflexionar acerca del estado en que se encuentran los estudios sobre la guerra en la actualidad.

Durante las jornadas se mencionó que aunque existe mucha bibliografía especializada que da cuenta del fenómeno, buena parte de esta se escribió durante los años del conflicto armado y los textos están planteados desde la militancia, los testimonios o el periodismo. Por otro lado, se llegó a la conclusión que aunque la guerra en El Salvador culminó hace más de 20 años, los esfuerzos para entenderla e interpretarla desde los ámbitos académicos son muy recientes:

«La experiencia centroamericana indica que los procesos de recuperación de la memoria de la violencia política (guerra civil) entre las décadas del setenta-ochenta con sus altibajos se ha trabajado con mayor prolijidad desde movimientos y/o asociaciones civiles, que desde las academias (universidades)». ${ }^{6}$

Lo anterior es importante porque es necesario partir del reconocimiento de que buena parte de los textos disponibles tienen una clara intencionalidad política; sin embargo, también hay que reconocer que estos tra-

5 Jorge Juárez Ávila, Coord. «Historia y debates sobre el conflicto armado salvadoreño y sus secuelas, Unidad de Investigaciones de la Guerra Civil Salvadoreña» (San Salvador: Instituto de Estudios Históricos, Antropológicos y Arqueológicos de la Universidad de El Salvador/ Fundación Friedrich Ebert, 2014), 11.

6 Miguel Ayerdis, «Memorias de la revolución: resituando el pasado en el presente (reflexiones para su estudio)» en Jorge Juárez Ávila, Coord. «Historia y debates sobre el conflicto armado salvadoreño y sus secuelas, Unidad de Investigaciones de la Guerra Civil Salvadoreña», 161. 
bajos son fuentes imprescindibles para construir las nuevas interpretaciones del conflicto armado salvadoreño desde la academia. El mencionado carácter de los textos es relevante para entender las dinámicas políticas y sociales que predominaron por aquellos años y que dieron origen a esas interpretaciones.

Así — después de una revisión de buena parte de los textos sobre la guerra en El Salvador - se puede afirmar que el material es diverso y va desde ensayos y artículos periodísticos, testimonios de actores en el conflicto, tanto militantes del Frente Farabundo Martí para la Liberación Nacional (FMLN) como de algunos miembros de las Fuerzas Armadas de El Salvador (FAES), hasta escritos académicos.

En términos generales, se puede observar que los textos tienen una clara intención política; es decir, tenían el objetivo de explicar y, en ocasiones, justificar la necesidad de pelear la guerra. Cuando estas obras fueron escritas se buscaba transmitir la idea de que la lucha era legítima e ineludible, dado que literalmente se habían agotado los caminos posibles para llevar a cabo transformaciones políticas, económicas y sociales.

Asimismo, en las fuentes se identifican dos interpretaciones de la guerra, dependiendo la postura política de quien enuncia: la primera es referente a la idea de que la guerra fue el último recurso y que, en este sentido, se trataba de un mal necesario por el cual se debía transitar para poder construir un nuevo orden social.

La segunda tiene que ver con la idea de que se hacía la guerra para proteger al Estado y la nación de las amenazas que lo ponían en peligro; esta amenaza era definida de distintas maneras, pero hay una coincidencia en cuanto al peligro que representaba, ya fueran comunistas, subversivos, terroristas o el enemigo interno. En ambos casos, hay una coincidencia discursiva en cuanto a que, finalmente, de lo que se trataba era de conseguir la paz.

Es claro cómo las narrativas sobre el conflicto armado en El Salvador son muy politizadas; sin embargo, lo anterior no tiene que ver con una mala intención o voluntad de quienes hicieron esos trabajos, sino con el momento en que fueron escritos, así como con quiénes eran y cuáles eran sus intereses. 
Así, después de enunciar brevemente lo que se ha hecho, debo mencionar que los objetivos de la investigación que desarrollo - y cuyas líneas generales presento en este artículo- son, en primer lugar, abordar el tema de la guerra desde una perspectiva distinta a lo que hasta aquí se expuso. Por otro lado, busco demostrar que a la guerra no se va de manera espontánea: hay procesos de radicalización política, del cual son responsables tanto el Estado y sus grupos afines (por un lado) y, por el otro, las agrupaciones político - militares que optaron por el camino de la violencia organizada, como una manera de disputar y obtener el poder político. Finalmente, pretendo argumentar que la violencia que ocurre en una guerra es la profundización de dinámicas de violencia preexistentes. Siguiendo con lo anterior, se puede evidenciar que la violencia en la guerra tiene lógica, esta no es irracional.

\title{
La violencia en la historia de El Salvador. La década de los 70 y la violencia legítima
}

\author{
los reyes de la página roja, $[\ldots]$ \\ los hacelotodo, los vendelotodo, los comelotodo, \\ los primeros en sacar el cuchillo. \\ Roque Dalton, Poema de amor.
}

Durante los últimos años del siglo XX, Centroamérica ocupó un lugar importante en el interés internacional; el mundo observaba los acontecimientos que parecían el inicio de grandes transformaciones. Por un lado, en la década de los 80 hubo quienes pensaron que el triunfo de la revolución nicaragüense abriría la puerta a grandes cambios en la región y, por el otro, quienes veían al istmo como el último escenario de la Guerra Fría: consideraban que se debía impedir la victoria de las revoluciones salvadoreña y guatemalteca y revertir el proceso nicaragüense.

En los 90, durante la posguerra, la región pasó de las páginas de política a las de nota roja. Han pasado los años, el istmo se ha transformado, los regímenes políticos han cambiado: de los Estados definidos como autoritarios se transitó a los regímenes democráticos, característicos de la nueva 
«era global». ${ }^{7}$ Sin embargo, en ocasiones pareciera que una de las constantes en la historia centroamericana ha sido la violencia.

Lo anterior puede observarse en la historia reciente de El Salvador, país con una larga historia de violencia. Sin embargo, aunque se afirme que esta ha estado presente a lo largo del tiempo, es necesario precisar que su ejercicio no siempre ha sido igual; se ha modificado de acuerdo a cambios suscitados en el país, a los actores que la ejercen, a los objetivos que estos persiguen y, sin duda, también a las transformaciones en el ámbito internacional.

En la actualidad, El Salvador es considerado uno de los países más violentos del mundo, debido, sobre todo, a la enérgica confrontación entre las pandillas Mara Salvatrucha 13 y el Barrio $18 .{ }^{8}$ El ambiente de violencia social, generalmente, es interpretado como efecto de la guerra de la década de los 80. Sin embargo, se puede trazar una línea de continuidad en la historia del país centroamericano, en la que la violencia social ha sido una

7 En el texto, la autora sostiene que el mundo transitó de una organización bipolar, durante la Guerra Fría, a una unipolar, a partir de la "caída del socialismo real». Las democracias formales han resultado bastante funcionales para este tipo de reorganización. Gestionadas por élites políticas que alcanzan el gobierno con cierta legitimidad — en elecciones manipuladas mediáticamente, con mucha ingeniería electoral y fuerte despolitización social — se asocian y articulan con la red corporativa y sus intereses económicos formando verdaderas oligarquías (entendidas estas según su acepción más clásica; es decir, como gobierno de los ricos). Cfr. Pilar Calveiro, Violencias de Estado. La guerra antiterrorista y la guerra contra el crimen como medios de control global (Buenos Aires: Siglo XXI, 2012), 57.

8 El fenómeno de las pandillas en El Salvador es muy complejo. Basta decir que estas agrupaciones juveniles surgieron en Los Ángeles, California, Estados Unidos. En un principio, se trataba de agrupaciones de latinos y latinas que hacían frente a la violencia que contra ellos infligían otros grupos étnicos, también agrupados en asociaciones pandilleriles. El Barrio 18 aglutinó a la población latina en general y, posteriormente, las y los salvadoreños se agruparon en la que fue conocida como Mara Salvatrucha 13 (MS 13), en la que solo se admitía a personas llegadas de El Salvador. En algún momento, el Barrio 18 y la MS 13 devinieron en enemigos a muerte. Después de culminada la guerra en El Salvador, en la década de los 90, el gobierno de George H.W. Bush realizó deportaciones masivas. El problema se ha agudizado porque los gobiernos en turno (ya sean de derecha o izquierda) le han apostado a medidas punitivas y no han abordado la problemática de la juventud salvadoreña de manera integral, apostando a otras alternativas que no pasen por el uso de la violencia. Se puede encontrar información importante respecto de las maras en el periódico electrónico El Faro, de El Salvador, que son los únicos que al día de hoy han podido documentar el problema de la violencia, no solo en El Salvador, sino en el llamado triángulo norte (Guatemalas, El Salvador y Honduras) de Centroamérica: www.elfaro.net 
constante. Es decir, sostengo la hipótesis de que la violencia que priva hoy en el país no es sólo un efecto de la guerra, sino que tiene que ver con su propia constitución social. Lo anterior es relevante si atendemos la propuesta de Stathis N. Kalyvas ${ }^{9}$ referente a que la violencia que se despliega en una guerra civil ${ }^{10}$ es la profundización de dinámicas que existían y que eran previas al enfrentamiento armado.

En el presente artículo, no abundaré en lo relativo a la forma en que la sociedad salvadoreña se constituyó, de manera tal en que la violencia tuvo un lugar central. Basta apuntar que hacia finales del Siglo XIX, y principios del XX, los cuerpos de vigilancia (aún no constituidos formalmente como parte del Estado) tenían un poder efectivo y se reafirmaban a través del ejercicio de la violencia: los miembros de estos grupos tenían la posibilidad, por ejemplo, de infligir castigos fisicos en contra de quienes se suponía habían sido hallados en falta. El ejercicio de la violencia - y además una violencia exhibida - se volvió una práctica sistemática, dejó de ser una anomalía. Como plantea Patricia Alvarenga en su texto «Cultura y Ética de la violencia»: «La recurrencia de los abusos nos indica que éstos constituyeron parte esencial de la dinámica del poder, [...] respondieron a un proyecto de dominación que, [...], generaba también una ética particular». ${ }^{11}$ Fue a partir de la recurrencia de esas prácticas, así como de la nula sanción a estas desde

9 La obra de Stathis N. Kalyvas, La lógica de la violencia en la guerra civil, es un estudio académico en el cual argumenta que sí existe una lógica en la violencia que se inflige en una guerra, contraviniendo la tesis de que la violencia desatada en las conflagraciones es irracional. Según el autor, el grado de terror alcanzado en un conflicto armado es una profundización de dinámicas de violencia preexistentes; así, mucha de las violencias que ocurren en la guerra, a veces, tienen poca relación con las razones por las cuales se desató el conflicto y sí con la propia historia de quienes están en disputa.

10 Es importante hacer la precisión de que se trata de una guerra civil porque, generalmente, cuando hay invasiones o enfrentamientos (entre dos o más estados) la tecnología juega un papel definitorio, haciendo la experiencia de matar algo impersonal que se puede efectuar a larga distancia; un ejemplo de ello son los bombardeos. Ambos escenarios son violentos; sin embargo, en el caso de las guerra civiles, muchos de los enfrentamientos son cuerpo a cuerpo entre personas que, por lo menos, tienen una historia en común, la que en muchos de los casos es personalísima.

11 Patricia Alvarenga, Cultura y ética de la violencia. El Salvador, 1880-1932 (San Salvador: Dirección de Publicaciones e Impresos, Consejo Nacional para la Cultura y el Arte, CONCULTURA, 2006). 
el Estado, que se construyó lo que Alvarenga menciona en su texto y define como "cultura de la violencia». Esta tiene que ver con identificar cuáles son los códigos sociales que regulan y/o toleran el ejercicio del terror como controlador de las dinámicas sociales:

«La violencia no debe analizarse en términos exclusivamente cuantitativos —número de integrantes del aparato represivo, armamento, etc. - sino también y, especialmente, cualitativos. No basta con establecer que la violencia es crucial para mantener el orden; es necesario entender cómo se genera y se reproduce». ${ }^{12}$

Lo anterior me parece fundamental para explicar el porqué la de El Salvador ha sido definida como una sociedad violenta, incluso desde mucho antes de los sucesos de 1932 o de la década de los 70, que se caracterizó por la violencia represiva, o la guerra de los 80 . El hecho de que el Estado delegara su capacidad de control y vigilancia a los propietarios, hizo que la resolución de los conflictos, en muchas ocasiones, no pasara por las instancias de gobierno. Esto posibilitó una forma de sociabilidad en donde el conflicto social se dirimía de manera directa, algo así como la práctica de justicia por mano propia.

Aunque hasta aquí he mencionado que se puede trazar una línea de continuidad en el ejercicio de la violencia a lo largo de la historia salvadoreña, hay que enfatizar (aunque parezca obvio) en el hecho de que existen diferencias en este ejercicio en un escenario de guerra y en uno de paz. ${ }^{13}$

En enero de 1981, el FMLN declaró la guerra al Gobierno de El Salvador. La «Ofensiva Final» significó el inicio formal de una guerra que ya se prefiguraba desde la década anterior, cuando se fundaron las organizaciones político-militares que constituyeron el FMLN y el Estado reprimía duramente cualquier indicio de oposición política.

12 Patricia Alvarenga, Cultura y ética de la violencia. El Salvador, 1880-1932.

13 La noción de paz a la que hago referencia es muy general: se trata de la ausencia de una guerra declarada. 
Es en este sentido, es necesario evidenciar cómo la violencia del Estado y la de las organizaciones político-militares no fue la misma - no solo en cuanto a capacidad y magnitud que tenía cada uno de los que la ejercieron-, sino por la forma en que se construyó al enemigo contra el que sería lícito luchar, a ese «otro» que sería preciso eliminar.

La violencia que se gestó a partir de la década de los 70, y que culminó con la guerra de la década siguiente, estaba vinculada (por lo menos discursivamente) al ejercicio político. Es decir, aunque hubo periodos en que el ejercicio de la violencia se hizo desde el poder, o por grupos asociados a él - con el objetivo de castigar a la oposición, como ha sido mencionado en líneas anteriores-, la violencia siempre estuvo presente para dirimir conflictos en la vida cotidiana.

Lo interesante, y complicado, de este periodo es que aunque la violencia tuvo un signo político, no fueron solamente las instancias del estado, o los grupos políticos que se oponían al gobierno, quienes la ejercieron; ésta fue ejecutada por diversos sectores que se sintieron interpelados en la necesidad de defender algo que les sería arrebatado. Es decir, el ejercicio de la violencia durante la década de los setenta empezó a encaminarse hacia la pelea de una guerra y, en este sentido, las prácticas que de por sí existían se masificaron y profundizaron.

Así, por un lado, numerosas personas, sobre todo jóvenes, se identificaron con el discurso de las izquierdas y, poco a poco, se involucraron en la conformación de las distintas estructuras de éstas y, por otro lado, muchos de los grupos anticomunistas que se formaron y consolidaron durante esos años, estaban integrados por hombres y mujeres que decidieron defender a su país de la amenaza comunista, sin que ninguna instancia del gobierno les obligara a ello.

Del lado de la insurgencia -y un poco también desde el punto de vista oficial-, la violencia fue concebida a partir de la conciencia del derecho 


\section{legítimo a la insurrección, o levantamiento armado, como forma de con- seguir la transformación política. ${ }^{14}$ Asimismo, para el caso abordado en mi}

14 Para explicar la idea de la legitimidad de la insurrección y el uso de la violencia para el cambio político, son de mucha utilidad las reflexiones que respecto del término/fenómeno «revolución» hace Reinhart Koselleck en Futuro Pasado. Cfr. Reinhart Koselleck, Futuro pasado: para una semántica de los tiempos pasados (Barcelona: Paidos, 1993). Según el autor, las primeras revoluciones modernas — como la industrial - tenían el objetivo de restaurar un orden que había degenerado. En esos tiempos, los conceptos para explicar las transformaciones de orden político, que no de orden total, eran revuelta, rebelión o guerra civil. Se trataba de fenómenos que podían cambiar los modos o formas de gobierno, pero no la estructura social. La guerra civil que evocaba el desorden del pasado.

En este contexto, en teoría, siempre había peligro de que ocurriera una guerra civil, lo cual nos remite a la idea del estado de naturaleza. Así, el pacto social (a través del cual nació el Estado) buscaba terminar con esa guerra perpetua porque el Estado soberano tendría la potestad de usar la fuerza para garantizar la paz. Las revoluciones fueron reprimidas como rebeliones porque no se pensaba que alguien del pueblo pudiera acceder al poder. Solo los iguales son libres; solo los gobernantes pueden gobernar, como menciona Hannah Arendt en su texto Sobre la Revolución. Cfr. Hannah Arendt, Sobre la revolución, (Madrid:Alianza, 1988).

Fue con la Ilustración que se empezó a considerar, en el sentido de novedad, a la revolución. Lo anterior coincidió con el cambio de idea del tiempo histórico: este se volvió lineal. Así, hasta antes de la Ilustración, la idea del tiempo era cíclica, por lo que los cambios políticos tenían el objetivo de restaurar.

Según Koselleck, fue después de la Revolución Francesa, en 1789, que el término revolución se volvió abstracto y general. A partir de entonces, se buscaba transformar el Estado clasista, incluso con el uso de la violencia. En este sentido, es claro que hay ocasiones en que los términos de reforma o revolución convergen, ambos buscan la transformación del Estado, aunque en distintos niveles. Sin embargo, a partir de esa coyuntura se pasó de la idea de revolución política a revolución social. La causa social, poco a poco, fue cobrando relevancia. (Por eso, decía Arendt, toda revolución busca la libertad, más que la igualdad).

El concepto de revolución se volvió extensivo al resto del mundo, lo que trajo como consecuencia el que las revoluciones posteriores, o muchas de ellas, fueran vistas como parte de un mismo proceso que comenzó con la Revolución Francesa. Asimismo, como parte de esa novedad, la revolución se desvinculó totalmente del pasado para plantear la construcción de un futuro que en poco, si no es que nada, se parecería al pasado. Además de ser un elemento de cambio en el tiempo histórico, la revolución implicaba una aceleración de este, un revolucionar.

En este contexto, apareció un nuevo sujeto que era el encargado de llevar a cabo esta aceleración, un sujeto activo, el revolucionario: «La unión entre perspectivas filosófico-históricas universales y compromisos específicamente revolucionarios hace comprensible también la razón por la que se discute y convoca cada vez con más frecuencia el inicio planificado de una 'revolución, en el sentido concreto de un levantamiento, sin que por ello perjudique a su éxito" (en Koselleck, Op. Cit.). La conclusión de este proceso, a decir de Koselleck, fue la revolución rusa de 1917. Lo que hay de fondo en esa concepción de la revolución es el considerar que el realizarla es legítimo; es decir, que se tiene el derecho de cambiar el orden de las cosas si este nos parece injusto para construir un futuro distinto al presente-pasado que se pretende cambiar. Por ello, para llevarla a cabo, puede utilizar la violencia organizada. 
investigación, es importante añadir que la idea de que el uso de la violencia era legítima, también tuvo qué ver con la manera en que se configuró el mundo después de la Segunda Guerra Mundial, durante la Guerra Fría, que fue el escenario en que se libró la guerra de El Salvador, de los años ochenta.

Como menciona Pilar Calveiro, en su texto Violencias de Estado, el mundo bipolar estaba sostenido por las siguientes nociones:

La organización bipolar reivindicaba lo estatal, lo público y lo político como posibles principios de universalidad. Admitía la lucha, la confrontación y la revolución, en tanto formas válidas de la práctica política. [...] Tendía a pensar la realidad según esquemas binarios: explotados y explotadores, justo e injusto, correcto e incorrecto. Reivindicaba la disciplina, la razón y el esfuerzo como virtudes deseables en los individuos. ${ }^{15}$

Siguiendo con lo anterior, es preciso apuntar que esa confrontación global, tuvo su correlato en los gobiernos autoritarios de América Latina, cuyo signo fue el del terror y la violencia política:

Así pues, la Guerra Fría, en el ámbito internacional y la Guerra sucia en el continente fueron procesos de mutua correspondencia. De ambas guerras resultaron ganadores y perdedores, pero es preciso señalar que la derrota militar y política de los proyectos alternativos latinoamericanos se obtuvo en el contexto de políticas de terror que marcaron profundamente a las sociedades de nuestros países para inducirlas a la inmovilidad y a la obediencia. El miedo y la impunidad del Estado quedaron grabados en ellas como una señal todavía visible, que se puede reconocer y que convoca simultáneamente a la parálisis y, cada vez más, a la resistencia. ${ }^{16}$

Asimismo, es fundamental mencionar que, en el contexto de la Guerra Fría, durante la década de los cincuenta y sesenta, El Salvador expe-

15 Pilar Calveiro, «Violencias de Estado. La guerra antiterrorista y la guerra contra el crimen como medios de control», 64 .

16 Pilar Calveiro, «Violencias de Estado. La guerra antiterrorista y la guerra contra el crimen como medios de control», 46. 
rimentó un importante crecimiento económico que tuvo como una de sus consecuencias más relevantes el que un sector de la población experimentara la necesidad de involucrarse en el espacio publico que, hasta entonces, estaba restringido. Esto, aunado al trabajo que realizó la iglesia, tuvo como resultado la construcción de un ambiente propicio para que el discurso de las organizaciones político militares, referente a que la violencia organizada era una opción viable ${ }^{17}$ para el cambio político, le hiciera sentido a muchos de los y las salvadoreñas.

Es importante considerar que aunque existan las condiciones que se han planteado como propicias para iniciar una revolución: pobreza, así como la existencia de un estado que puede ser caracterizado como autoritario y represor, ésta no siempre ocurre. El caso de El Salvador nos permite observar cómo fue determinante la presencia de los grupos guerrilleros para construir esa situación. La década de los setenta fue eso: la preparación, consciente, de una guerra. Así, se aprovechó la organización y disposición existente de las personas y ésta se radicalizó. Esta década fue de organización y acumulación de fuerza, no sólo en términos políticos sino también materiales.

Por cuestiones de espacio no abordaré con profundidad lo relativo a cómo tanto la izquierda y la derecha, retomaron en la década de los setenta los sucesos de 1932 como referentes ideológicos, para justificar el uso de la violencia; sólo mencionaré superficialmente cómo fue durante esos años que se llevó a cabo la construcción de un otro, que fue definido como el enemigo contra el que era preciso luchar para construir un nuevo orden social o para defender el status quo.

En un primer momento es importante precisar que, contrario a lo que comúnmente se cree, la derecha no fue un bloque homogéneo; más bien hubo una diversidad de posturas que, sin embargo, coincidieron en su declarado anticomunismo. La diversidad que fueron las derechas compartía la conciencia de que los grupos políticos de oposición, desde los demócratas

17 El triunfo de la revolución cubana había demostrado, de acuerdo a la interpretación de muchas personas por aquellos años, cómo la violencia revolucionaria sí era una vía exitosa para llevar a cabo las transformaciones que, según sus planteamientos políticos, el país necesitaba. 
hasta los más radicales como las organizaciones político-militares, representaban un peligro para el país. Lo anterior constituía un problema muy serio porque, desde su perspectiva, las y los militantes de izquierda no eran simples desestabilizadores; en el fondo ellos veían que los "valores de la civilización occidental", la propiedad privada y la religión católica, que consideraban los únicos y correctos, peligraban seriamente en caso de que la izquierda lograra tomar el poder. De tal suerte que con la justificación de que el estado ejercía el monopolio de la violencia, era lícito echar mano de ésta para defender al país de las amenazas que se cernían sobre él.

Aunque muchos de los grupos que se formaron por estos años también presentaron su oposición al gobierno salvadoreño -como el Frente Agropecuario de la Región Oriental (FARO) que se contrapuso al intento del presidente Arturo Armando Molina de llevar a cabo una Reforma Agraria, en 1976-, coincidían con éste en su postura anticomunista y en la conciencia de que los enemigos eran aquellos y aquellas a quienes calificaron como subversivos, terroristas. Y como en su lectura política el bien mayor era defender al estado, a cualquier costo, de aquellos que le amenazaban se reafirmó la idea de la necesidad de destruir a quienes ponía en peligro al país. Al final, el uso de la violencia, también organizada, adquiría legitimidad en el entendido de que se debía sacrificar a algunos y algunas, en aras de salvar a la mayoría.

Por otro lado, los grupos políticos militares de izquierda construyeron, bajo el convencimiento de que el uso de la violencia era legítimo, la necesidad de pelear una guerra. Se argumentó que tomar las armas constituía el "último recurso", después de que todas las opciones institucionales para llevar a cabo cambios políticos fueron cerradas; sin embargo, es interesante ver cómo, independientemente del hecho concreto de que efectivamente resultaba prácticamente imposible la transformación política a través de las vías institucionales, los grupos guerrilleros tenían el objetivo de disputar el poder a través de la violencia; es decir, se prepararon de manera consciente no sólo para ir a la guerra, sino para propiciarla.

Entonces, había que justificar la necesidad del uso de la violencia. Lo anterior no tiene que ver con que quienes se organizaron en torno a las 
agrupaciones político-militares, eran personas de talante violento, sino con lo que ya se ha mencionado a lo largo de este artículo: se trataba de otro momento en la historia, en el que la violencia, en algunos casos, también era parte de un ejercicio político radical, dado que las vías institucionales no resolvían la profundidad de los problemas. Asimismo, hay que dar cuenta de que uno de los elementos que se puede destacar en las insurgencias, por lo menos en las latinoamericanas, es que la militancia era muy joven y, además, se la puede definir como "rupturista": es decir, esa generación estaba convencida de que debía terminar con el orden existente y construir uno nuevo, a través de la revolución. Al respecto, Hannah Arendt, en su texto Sobre la violencia, hace mención de esta generación, tomando como referencia a los movimientos estudiantiles de la década de los sesenta.

Lo anterior quedó de manifiesto con el golpe de estado de 1979, en el que ninguna de las organizaciones político militares que después conformarían al FMLN negoció ni colaboró, por lo menos de manera abierta, con la Junta Revolucionaria de Gobierno. Así, en la década de los setenta, desde las derechas -y también desde la izquierda- se construyó, a partir de sus discursos y acciones, la idea de que pelear una guerra no sólo era necesario sino inevitable. ${ }^{18}$

\section{La lógica de lo irracional: guerra y violencia en El Salvador}

Como es sabido, la guerra en El Salvador inició formalmente en enero de 1981. Los enfrentamientos que empezaron a darse en el campo de batalla que, como fue mencionado, se configuraron en los años precedentes, tuvieron su correlato en un creciente clima de polarización política y social en que, los unos guerrilleros, revolucionarios, luchaban en contra de los que construyeron como los otros, el gobierno, caracterizados como los represores

\footnotetext{
18 En este punto, me parece muy importante precisar que el hecho de argumentar que tanto la izquierda como la derecha, la gubernamental así como la que no lo era, ejercieron acciones de violencia y se prepararon — de manera consciente para pelear una guerra - no significa que sus violencias sean equiparables (véase la nota 27).
} 
y asesinos; y, por el otro lado, el estado, "garante del estado de derecho", buscaba terminar a los que había definido como los otros, comunistas, terroristas, subversivos, en fin, el enemigo interno. ${ }^{19}$ Así, casi de manera inevitable, se colocaron los y las salvadoreñas de uno u otro lado, aunque éstos no lucharan en el frente:

... la guerra supone una polarización social, es decir, el desquiciamiento de los grupos hacia extremos opuestos. Se produce así una fisura crítica en el marco de la convivencia, que lleva a una diferenciación radical entre ‘ellos’ y 'nosotros', según la cual ‘ellos' son siempre y de antemano ‘los malos', mientras 'nosotros' somos 'los buenos'. [...] La polarización supone el exacerbamiento de los intereses sociales discrepantes, y termina arrastrando todos los ámbitos de la existencia: las personas, los hechos y las cosas ya no se miden por lo que son en sí, sino por si son nuestras o de ellos y por lo que representan a favor o en contra para la confrontación. Desaparece así la base para la interacción cotidiana. ${ }^{20}$

Lo anterior es sólo un ejemplo de cómo la guerra trastoca las relaciones cotidianas en la sociedad, porque de lo que se trata es de un ejercicio extremo de violencia política; es decir, aunque a través de la violencia se estaba haciendo política. ${ }^{21}$

La contrainsurgencia, los enfrentamientos armados, la violencia extrema, ejercida de un lado y del otro, a la que estuvo expuesta toda la sociedad -tanto de manera directa, como indirecta-; la interpretación maniquea de la realidad, en que unos eran los buenos y otros los malos, sin espacio para

19 Me ocupo de cómo fueron construidos «los otros» contra los que se debía pelear, y a los que incluso se debía aniquilar, en el tercero y cuarto capítulos de mi trabajo de investigación. Ahí expongo cómo esta construcción también fue parte de una estrategia de radicalización, de cada una de las partes, que al final fundamentó la idea de la necesidad de pelear una guerra. 20 Ignacio Martín-Baró, comp. Psicología social de la guerra (San Salvador: UCA Editores, 2000), 29. En este punto me parece importante apuntar que es necesario abordar la discusión en torno a la relación entre violencia y política que, en décadas anteriores, no se encontraba en disputa como ocurre al día de hoy.

21 Ignacio Martín-Baró, comp. Psicología social de la guerra, 15. 
las opciones matizadas; la polarización política y social, no fueron transformaciones aisladas. Se trató de la construcción de una lógica mediada por la violencia: la guerra es capaz de crear su cultura y, en este sentido, tiene su propia racionalidad:

Esta extensión y prolongación de la guerra ha hecho que su impacto alcance a la totalidad de la población, directa o indirectamente. Es dificil encontrar hoy en El Salvador alguna familia que no tenga algún hijo en la guerra, sea en un bando o en el otro, o que no haya sufrido en carne propia el impacto de la violencia, de la represión o de la muerte. ${ }^{22}$

Aunque generalmente la guerra es caracterizada por la violencia y el caos y, en este sentido, se la define como irracional, debo hacer énfasis en el hecho de que existe una lógica de la guerra, en que los valores tradicionales y formas de organización social son trastocados. En este sentido, se puede afirmar que la violencia ejercida -por los bandos involucrados, en este caso el FMLN y el gobierno salvadoreño- no fue de ninguna manera fortuita o irracional:

Poner el foco de forma abrumadora sobre las metáforas de la anarquía y la polarización nos ha hecho dejar de lado la dimensión crítica de las guerras civiles: el hecho de que ellas ofrezcan poderosos incentivos para la producción de violencia "indirecta" mediante civiles "ordinarios". Para la gran cantidad de gente que no está sedienta de sangre de un modo natural y que aborrece el verse implicada en la violencia de forma directa, la guerra civil ofrece unas oportunidades irresistibles para hacerles daño a los enemigos de todos los días. Es esta banalidad de la violencia, por parafrasear a Hannah Arendt, la que les da a las guerras vivales una buena parte de sus espantosas connotaciones. ${ }^{23}$

Se puede descifrar la lógica de la violencia en la guerra porque, contrario a lo que se piensa, lo que ocurre en una guerra no son sólo -o sobre 
todo- de actos irracionales llevados a cabo por psicópatas o gente enferma; ${ }^{24}$ se trata de una racionalidad determinada, que tiene métodos específicos para alcanzar objetivos concretos que, la mayoría de las veces o en el caso que nos ocupa, son políticos: "Está bien comprobado que la utilización de la violencia no es atribuible tanto a pulsiones destructivas o a personalidades psicópatas cuanto a su valor instrumental en una determinada situación para la consecución de lo que se pretende". ${ }^{25}$

Las acciones contrainsurgentes que, en muchas ocasiones terminaron en masacres, desapariciones forzadas (incluidas las de infantes), ${ }^{26}$ detenciones arbitrarias, violencia sexual sobre todo contra las mujeres, ejecuciones extrajudiciales, por un lado y, purgas y ajusticiamientos ejemplares, por el otro, constituyeron el paisaje de El Salvador en guerra. ${ }^{27}$

24 Con respecto a la supuesta irracionalidad de la guerra, llama la atención que el informe de la Comisión de la Verdad haya sido titulado "De la locura a la esperanza», como si los años de la guerra perteneciesen a dinámicas que por irracionales, por estar en el ámbito de la locura, son ininteligibles.

25 Ignacio Martín-Baró, Comp. Psicología social de la guerra, 29.

26 En mi tesis para obtener el grado de Maestra en Estudios Latinoamericanos «Las niñas y los niños desaparecidos del Pulgarcito. Desaparición forzada de infantes durante la guerra en El Salvador (1980-1984)", como su título indica, abordé con profundidad el tema de la desaparición forzada de infantes, durante la guerra. A partir de la reconstrucción de cuatro grandes operativos militares en el que desaparecieron niños y niñas, y de la identificación de varias «rutas de desaparición», llegué a la conclusión que la desaparición de infantes puede ser calificada de "forzadas» porque el Estado es responsable de ellas. Así, aunque no haya existido una orden explícita para separar a los menores de sus familias y entornos comunitarios, se puede fincar esa responsabilidad en tanto que obedece a lo que se puede denominar «lógica de la guerra»; es decir, en el ambiente de polarización que ha sido referido en este proyecto, los militares veían a los guerrilleros (y la población avecindada en zonas de conflicto) como el otro que se podía y debía eliminar. De esta manera, no necesitaban que se les ordenara explícitamente realizar tal o cual acción, ellos tenían libertad para asesinar, violar, raptar porque el fin último de la guerra era aniquilar al otro u otra. Las primeras «mentes y corazones» que fueron ganadas, como señalaba la contrainsurgencia, fueron las de los ejecutores de la guerra. 27 No pretendo equiparar la violencia gubernamental con la de la guerrilla; es evidente que esta fue desproporcionada y asimétrica. Sin embargo, es cierto que, en muchas ocasiones, se obvia que el FMLN también ejerció la violencia y que este ejercicio era parte de su estrategia revolucionaria. Por otro lado, me parece importante problematizar algunas de las interpretaciones que se construyeron hacia el final de la guerra en la línea de la teoría de los «dos demonios", de acuerdo a la cual en la guerra lo que ocurrió fue el enfrentamiento de dos fuerzas (dos demonios) y que en medio había un sinnúmero de personas cuyo único papel fue el de víctimas, porque no pertenecían ni a uno ni a otro bando. No coincido en esta for- 
En sus formas más evidentes que son el asesinato político y la tortura, la deshumanización no es un mero resultado accidental de la guerra, sino un recurso que ha ocupado un lugar central en la estrategia de contrainsurgencia. El mismo hecho de matar, aunque sea en combate y por una causa que es o se cree justa, es también deshumanizante. ${ }^{28}$

Siguiendo con lo anterior, lo que hay de fondo en la lucha entre un estado y un grupo insurgente que lo interpela es también una disputa cultural.Así, la guerra no se pelea sólo en el campo de batalla, pero el campo de batalla es también el escenario de una guerra cultural en que las partes antagónicas defienden una determinada forma de construcción social, a través del uso de la fuerza; Como afirma Antonius Robben, para el caso de la represión que ejerció la dictadura argentina y que bien puede ayudar a entender la guerra salvadoreña: "La guerra cultural legitimaba cuanta violencia fuera necesaria para conseguir la victoria [...] [para el ejército] El objetivo, por tanto, no sólo era derrotar a la guerrilla insurgente, sino fundamentalmente erradicar un constructo cultural antagónico". ${ }^{29}$

En este contexto, se puede afirmar que la violencia fue instrumentalizada para obtener objetivos políticos concretos. Por el lado del estado, es un hecho que el uso de la violencia y el terror, tenía como objetivo destruir y reorganizar las relaciones sociales. De acuerdo con Daniel Feirstein, también a propósito del caso argentino, se trataba del uso de "una tecnología de

ma de interpretar el tenómeno porque considero que al plantear la guerra de esa manera, en primer lugar, damos por buena la afirmación que la capacidad de ejercer la violencia — tanto de los grupos disidentes como del Estado- era equiparable y eso no es cierto. Por otro lado, perdemos de vista toda la complejidad del fenómeno; por mencionar un ejemplo: las víctimas pueden ser victimas sin renegar de sus actividades políticas (incluidas sus acciones de violencia). En todo caso, lo que se debería señalar es que el Estado no debió actuar de la manera en que lo hizo, atendiendo a que una de sus responsabilidades es garantizar la seguridad de las personas bajo su potestad.

28 Joaquín Samayoa, «Guerra y deshumanización: una perspectiva psicosocial» en Ignacio Martín-Baró, Comp. Psicología social de la guerra, 43.

29 Antonius C. G. M. Robben, Pegar donde más duele.Violencia política y trauma social en Argentina (Barcelona: Anthropos, 2008) 205. 
poder" ${ }^{30}$ que era capaz de alcanzar sus objetivos a través del aniquilamiento de colectivos humanos, y el terror que estas acciones generaran. ${ }^{31}$

Así, el fondo político de esta disputa, que ha sido definida también como cultural, radica en el cuestionamiento de la legitimidad del estado y la capacidad de los grupos armados, en este caso del FMLN, para disputar al gobierno el control de éste. Lo anterior, tenía que ser necesariamente a través de la violencia, porque el gobierno no cedería voluntariamente su capacidad para controlar el monopolio de la violencia: ${ }^{32}$

El uso de la violencia por otros actores políticos comporta el cuestionamiento [al estado] de este monopolio, que puede ocurrir para la fundación de un nuevo orden y un nuevo derecho. Cuando es así, se podrían diferenciar dos violencias, simétricas en sus fines [el subrayado es mío, dado que de ninguna manera se debe equiparar la violencia de estado con la de los grupos insurgentes] aunque no necesariamente en su potencia ni en sus formas de ejercicio: una violencia conservadora del derecho vigente, que instrumenta el Estado, y otra violencia fundadora de un nuevo orden y un nuevo derecho, que se pretenden más justos. ${ }^{33}$

Si pensamos el fenómeno de la guerra también como la disputa entre dos constructos culturales, a través del ejercicio de la violencia política extrema, en donde el estado usó una tecnología de poder que pretendió reeducar la sociabilidad, será más fácil entender el porqué de la crueldad de

30 Por «tecnología del poder», concepto retomado por Feierstein se entiende: «una forma peculiar de estructurar — sea a través de la creación, destrucción o reorganización- relaciones sociales en una sociedad determinada, los modos en que los grupos se vinculan entre sí y consigo mismos, y aquellos a través de los cuales construyen su propia identidad, la identidad de sus semejantes y la alteridad de sus 〈otros»». Cfr. Daniel Feierstein, El genocidio como práctica social. Entre el nazismo y la experiencia argentina. Hacia un análisis del aniquilamiento como reorganizador de las redes sociales (Buenos Aires: Fondo de Cultura Económica, 2007), 26.

31 Daniel Feierstein, El genocidio como práctica social. Entre el nazismo y la experiencia argentina. Hacia un análisis del aniquilamiento como reorganizador de las redes sociales, 13.

32 Aquí es importante hacer la precisión de que tomo una definición muy reducida del Estado, cuya característica principal es tener el monopolio del uso de la violencia.

33 Pilar Calveiro, "Antiguos y nuevos sentidos de la violencia y la política», en http://www. so000260.ferozo.com/pdf/lucharmada4.pdf, consultada en octubre de 2013. 
sus acciones. Con el sadismo, por mencionar un ejemplo, de la tortura se trataba de dar un castigo ejemplar, además de conseguir información para ganar la guerra; es decir, la crueldad en las acciones que los agentes de estado ejercieron no era una cuestión personal, o del carácter de quién ejecutaba las acciones, se trataba de la forma en que se debian hacer las cosas. ${ }^{34}$

La guerra cultural proseguía a través de la tortura, que no era un epifenómeno, un aspecto colateral o un trabajo sucio necesario, sino un elemento en toda regla de una estrategia global en la que el campo de batalla se extendía hasta abarcar el cuerpo humano, el yo y la mente. La tortura iba a culminar la victoria obtenida sobre el terreno al adentrarse en las mentes y la identidad de los derrotados, pues ahí era donde estaba más enraizada la cultura. ${ }^{35}$

Con las acciones de terror, se trató de eliminar ese algo que fue definido como nocivo para la estabilidad y salud de la sociedad. Pero no bastaba con eliminarles fisicamente, se trataba de borrar sus expresiones culturales, su forma de organización social que se contraponía a la forma de organización que defendía el estado.

La guerra $[\ldots]$ es $[\ldots]$ una estructura que persigue la desrealización de los constructos culturales y, simultáneamente, su reconstitución final. Con la guerra, en último extremo, se trata de determinar cuál de esos dos constructos culturales enfrentados va a gozar de la autorización de ambas partes para convertirse en real. ${ }^{36}$

34 Menciono el hecho de "conseguir información» porque la tortura está comúnmente asociada a los interrogatorios. Supuestamente, se tortura al detenido o a la detenida para obtener algún tipo de información relativa a sus actividades políticas, que coadyuve a desmantelar las organizaciones que son perseguidas por el Estado; sin embargo, por la forma en que esta es aplicada es evidente que la obtención de información no es el único objetivo.

35 Antonius C. G. M. Robben, Pegar donde más duele. Violencia política y trauma social en Argentina, 252.

36 Antonius C. G. M. Robben, Pegar donde más duele. Violencia política y trauma social en Argentina, 204. 
Si consideramos que la violencia estatal buscaba desarticular y desmovilizar, a través del terror y el miedo, se puede afirmar que las organizaciones político-militares de izquierda usaron la violencia no sólo como forma de defensa y para neutralizar el miedo, sino para destruir al que los grupos de izquierda caracterizaron como el régimen de opresión.

\section{Conclusiones preliminares}

La dinámica de la guerra que se peleó durante los años ochenta fue construida desde la década anterior, por acciones de violencia y represalias, de uno y otro lado. A la violencia estatal se contrapuso la violencia organizada. El desafío revolucionario no sólo implicó defenderse de los embates de los cuerpos represivos, sino el ataque a las instituciones que sostenía al estado, porque claramente el objetivo era propiciar la guerra: la guerra revolucionaria para la destrucción del estado existente y la construcción de uno nuevo, capaz de resolver los problemas por los que se había hecho necesario pelear una guerra.

No se puede entender la lógica de la violencia en la guerra, sin tomar en consideración cómo se configuró la idea de que ésta no sólo era necesaria, sino inevitable. Es decir, frente a la certeza de un orden social y político injusto se asumió, desde la izquierda, que las organizaciones político-militares, como representantes de ese nuevo universal abstracto, el revolucionario que encarnaba al pueblo, que tenían el derecho legítimo al uso de la violencia organizada para revolucionar, en el sentido planteado por Koselleck, el orden político y social y así construir uno nuevo.

Lo anterior, se configuró durante los años setenta, momento en el que ocurrió el resquebrajamiento del sistema político que caracterizó a El Salvador durante buena parte del siglo XX. Asimismo, se evidenció que lo que había sido considerado como un bloque homogéneo, no lo era: la derecha no era homogénea, por el contrario, era diversa y hasta contradictoria; sin embargo, pese a dicha heterogeneidad había la coincidencia en que se tenía que terminar con quienes trabajaban por transformar las estructuras 
políticas y económicas del país. Es decir, la derecha se preparaba para pelear una guerra.

Por otro lado, aunque la izquierda también proyectaba y se preparaba para ir a la guerra, es importante considerar que de ninguna manera la violencia de estos grupos se puede comparar con la violencia de estado y de las organizaciones afines a éste, toleradas e incentivadas por él; esta comparación no se puede hacer ni siquiera en sentido abstracto (porque se supondría que el estado no debería ser al mismo tiempo juez, para dirimir el conflicto social, y parte, como en los hechos fue), ni mucho menos en el plano fáctico, en cuanto a los recursos y la tecnología de que el estado dispone para ejercer la violencia.

La desaparición forzada, la tortura, las detenciones arbitrarias, las ejecuciones extrajudiciales, la exhibición de cuerpos torturados fueron parte de las tecnologías de poder que el estado usó destruir los lazos sociales. El miedo, como agente desmoralizante y también despolitizante. Así, con la destrucción de la posibilidad de que las personas emprendieran proyectos colectivos, se educó en una nueva sociabilidad enfocada en el ámbito privado e individual.

Al final, uno de los elementos que unió a la vieja institucionalidad con la nueva fue el terror de estado y cómo éste fue pedagógico. Así, la institucionalidad -renovada- salvadoreña se cimentó sobre la base de prácticas de violencia -como ocurrió hacia finales del siglo XIX-; sin embargo, en esta ocasión los efectos fueron más devastadores porque, en primer lugar, había una guerra con sus propias dinámicas y, en segundo término, inmediatamente después de que se firmaron los Acuerdos de Paz en 1992, se implementaron reformas de corte neoliberal, que resultaron excluyentes para la mayoría de la población. 


\section{REFERENCIAS BIBLIOGRÁFICAS}

Alexiévich, Svetlana. La guerra no tiene rostro de mujer. Barcelona: Penguin Random, 2016.

Alvarenga, Patricia. Cultura y ética de la violencia. El Salvador, 1880-1932. San

Salvador: Dirección de Publicaciones e Impresos, Consejo Nacional para la Cultura y el Arte, CONCULTURA, 2006.

Arendt, Hanna. Eichmann en Jerusalén. Un estudio acerca de la banalidad del mal. Barcelona: Editorial Lumen, 2003.

- "Sobre la violencia», Cuadernos de Joaquín Mortiz. México, D.F.: 1970. Sobre la revolución. Madrid: Alianza Editorial, 1988.

Calveiro, Pilar. Violencias de Estado. La guerra antiterrorista y la guerra contra el crimen como medios de control global. Buenos Aires: Siglo XXI, 2012.

Dalton, Roque. Las historias prohibidas del pulgarcito. México, D.F.: Siglo XXI Editores, 1997.

Feierstein, Daniel. El genocidio como práctica social. Entre el nazismo y la experiencia argentina. Hacia un análisis del aniquilamiento como reorganizador de las redes sociales. Buenos Aires: Fondo de Cultura Económica, 2007.

Hedges, Chris. La Guerra es la fuerza que nos da sentido. Madrid: Editorial Síntesis, Madrid, 2002.

Juárez Ávila, Jorge. Coord. Historia y debates sobre el conflicto armado salvadoreño y sus secuelas, Unidad de Investigaciones de la Guerra Civil Salvadoreña. San Salvador: Instituto de Estudios Históricos, Antropológicos y Arqueológicos de la Universidad de El Salvador/ Fundación Friedrich Ebert, 2014.

Kalyvas, Stathis N. La lógica de la violencia en la guerra civil, Madrid: Ediciones Akal, 2010.

Koselleck, Reinhart. Presente pasado: para una semántica de los tiempos pasados. Barcelona: Paidos Ibérica, 1993.

Martín-Baró, Ignacio. Comp. Psicología social de la guerra. San Salvador: UCA Editores, 2000. 
Ramírez, José Alfredo. El discurso anticomunista de las derechas y el estado como antecedente de la guerra civil en El Salvador (1967-1972), Tesis para obtener el título de licenciado en Historia, Universidad de El Salvador, San Salvador, 2008.

Robben, Antonius C. G. M. Pegar donde más duele. Violencia política y trauma social en Argentina. Barcelona: Anthropos, 2008.

Turse, Nick. Dispara a todo lo que se mueva. la verdadera guerra norteamericana en Vietnam. Madrid: Sexto Piso Ediciones, 2014.

Vela Castañeda, Manolo E. Los pelotones de la muerte. La construcción de los perpetradores del genocidio guatemalteco. México: El Colegio de MéxicoCentro de Estudios Sociológicos, 2014. 